\title{
Práticas avaliativas na sala de aula de línguas estrangeiras-adicionais na educaçáo básica: elaborando instrumentos com a participaçáo dos alunos
}

\author{
Maria Inêz Probst Lucena1* \\ Clarissa Mombach** \\ Fabíola T. Ferreira*** \\ Nádia Karina R. Ramos****
}

\begin{abstract}
Resumo
O objetivo deste artigo é apresentar algumas considerações acerca do uso de diferentes instrumentos e critérios de avaliação da aprendizagem na sala de aula de línguas. Nosso estudo está situado na Linguística Aplicada e, com base nos preceitos teóricos da área, procuramos considerar os desafios educacionais, na sala de aula de línguas do século XXI, discutindo nossas experiências desenvolvidas na realidade da Educação Básica em uma escola do sistema regular de ensino. Para tanto, apresentamos uma breve discussão teórica acerca das questôes que envolvem a avaliação em línguas estrangeiras/adicionais (LE/LA); em seguida, apresentamos exemplos de atividades avaliativas desenvolvidas nas aulas de Alemão, Espanhol e Inglês, contextualizando-as no espaço de aula em que ocorreram. Por fim, argumentamos a favor da diversidade de instrumentos, destacando a necessidade de repensar a avaliação na sala de aula de LE/LA, de modo que tal prática constitua-se cada vez mais como uma açáo inclusiva, e não o contrário.
\end{abstract}

Palavras-chave: avaliação da aprendizagem, línguas estrangeiras/adicionais, instrumentos de avaliação

Assessment practices in the foreign/additional language classroom in the regular school system: students' participation in the design of assessment tools

Abstract

The aim of this paper is to discuss the use of different tools and criteria for assessment of the foreign/additional language classroom. Drawing on an Applied Linguistics framework, the paper attempts to approach the reality and challenges of the language classroom in the regular school system. Theoretical aspects of assessment are briefly discussed and examples

* Professora de Inglês do Colégio de Aplicação da UFSC e da Pós-graduação em Linguística da UFSC. E-mail: Lucena.inez@gmail.com

** Professora de Alemão do Colégio de Aplicação da UFSC. E-mail: cmombach@terra.com.br

*** Professora de Espanhol do Colégio de Aplicação da UFSC. E-mail: fabiolatferreira@gmail.com

**** Professora de Inglês do Colégio de Aplicação da UFSC. E-mail: nadiakrramos@gmail.com 
of assessment tools used in the daily routines of German, Spanish and English lessons are provided. Finally, we argue for a diversity of tools in the language classroom, highlighting the need to rethink assessment practices in our given language learning context in order to contribute towards more inclusive assessment practices.

Keywords: learning assessment, foreign/additional languages, assessment tools

\section{Introduçáo}

Com base em uma perspectiva crítica da Linguística Aplicada, apresentamos exemplos de instrumentos de avaliaçáo da aprendizagem, elaborados a partir de nossas reflexóes, provenientes de um projeto de extensão, cujo objetivo principal é o desenvolvimento de materiais e atividades que auxiliem a ação avaliativa nas aulas de línguas estrangeiras/ adicionais (LE/LA) na escola regular. Utilizamos aqui o termo adicional, além do complemento estrangeira por entendermos que a língua alemá, a espanhola ou a inglesa - nosso objeto de ensino - não são mais ensinadas/ aprendidas de forma abstrata, especialmente no Sul do Brasil, contexto em que atuamos. Ao contrário, essas línguas são utilizadas por um grande número de pessoas para fazer práticas bem concretas, tanto na área da cultura, do turismo ou dos negócios (BLOCK, 2003), como em outros vários modos de interaçôes transnacionais, possíveis para uma parcela considerável de pessoas, nos dias de hoje, especialmente pelo uso das tecnologias. Assim, considerando que essas línguas fazem parte da vida social e pessoal dos indivíduos, são utilizadas para a comunicação entre povos e têm um papel central na formação cidadã, elas são línguas adicionais ao português (SCHLATTER; GARCEZ, 2009), uma vez que seu uso implica práticas sociais e, portanto, a experiência de aprendizagem de línguas está além do "acúmulo de conhecimento linguístico" (BLOCK, 2003, p. 57).

Nesse sentido, importa destacar que o conjunto de atividades avaliativas, discutido e apresentado neste artigo, foi desenvolvido numa perspectiva de uso da linguagem como prática social e busca contribuir, assim, com os desafios cotidianos ao fazermos inferências sobre o processo de ensino e aprendizagem quando precisamos tomar decisóes sobre o desempenho de nossos alunos em relação ao uso da língua nas açóes cotidianas. Nesses reptos reais, temos procurado discutir maneiras e formas de considerar a complexidade da sala de aula de línguas estrangeiras/adicionais durante o 
processo avaliativo, tentando contemplar a heterogeneidade existente nesse contexto específico.

$\mathrm{O}$ interesse na avaliação da aprendizagem tem sido impulsionado por pesquisas e estudos em Linguística Aplicada nos últimos anos, especialmente na última década, e importantes desdobramentos podem ser reconhecidos em nossa área (ver SCARAMUCCI, 2000, SHOHAMY, 2001, SCHALATTER; GARCEZ, 2009; 2012, entre outros). Com base em Garcez (2011), que juntamente com outros pesquisadores (ex. SCHALATTER; GARCEZ, 2009) vêm questionando o sentido educacional do ensino de línguas na escola regular, temos tentado entender também o sentido educacional da avaliação na sala de aula de línguas na escola regular, na sociedade contemporânea, pois, como destaca Lucena,

Há, sem dúvida, uma sociedade que apresenta novas necessidades e especificidades. Esse novo contexto exige uma avaliaçáo pautada em novos paradigmas que contemplem essa complexidade do sistema social chamado por Hall (1997) de globalização pós-moderna. Nessa nova sociedade, há uma sala de aula que inclui novas realidades [...] gera[n] do novas relaçôes na sala de aula de línguas que nos fazem repensar as normas a serem aplicadas. (LUCENA, 2012, p. 6)

Como a autora destaca, a avaliação na sala de aula de línguas precisa ser também entendida como uma atividade que opera em uma sociedade híbrida, moldada pelos fluxos transculturais e fluidos das relações sociais e econômicas. Nesse movimento, torna-se necessário entender a linguagem não somente como um conjunto rígido de itens e de normas fixas a ser aprendido e testado através de testes e exames padronizados. $\mathrm{O}$ uso da linguagem como prática social não pode ser entendida somente por sua coerência como um sistema fixo e asséptico, mas por sua coerência e negociação com a localidade em que opera. Portanto, a aprendizagem de línguas não pode ser mensurada através de padróes sintáticos e gramaticais, baseados em normas preestabelecidas e estipuladas como padrão. Com base em nossa experiência, passamos a observar que, muitas vezes, preceitos de racionalidade técnica podem fazer com que muitas atividades relacionadas aos aspectos sociais e culturais da vida dos alunos não sejam considerados na avaliação (LUCENA, 2006).

Interessam-nos, particularmente, formas mais democráticas de avaliação, em consonância com posiçóes políticas e com uma perspectiva pós-colonialista de ensino e aprendizagem de Línguas (PENNYCOOK, 
2001; LUCENA, 2006, 2012; SHOHAMY, 2001; SCARAMUCCI, 2000; SHALATTER e GARCEZ, 2009, 2012, entre outros). Procuramos entender a avaliação dentro de um contexto em que relaçóes de saber e de poder são efetivamente consideradas e, para tanto, discutimos como e por que avaliamos, para quem e de que maneira podemos desenvolver instrumentos mais condizentes com um contexto socio-histórico complexo, em que tudo está em fluxo, inclusive nossa prática (CAVALCANTI, 2006).

\section{A práxis - reflexóes conjuntas e práticas em sala de aula}

Este artigo é fruto do projeto de extensão Avaliação da aprendizagem em Lingua estrangeiraladicional: reflexóes e elaboração de instrumentos desenvolvido por uma professora de alemáo, uma de espanhol e duas de inglês. Além da discussão e da elaboração de diferentes instrumentos de avaliação, procuramos desenvolver um trabalho na formação de educadores, oferecendo oficinas e cursos para alunos-professores e para professores de línguas.

Os instrumentos e as práticas que discutimos aqui provêm de demandas da sala de aula, de conversas sobre o processo avaliativo com nossos alunos, de resultados de pesquisas anteriores (LUCENA, 2006) e de reflexóes acerca de nossa própria prática. Os registros e os dados apresentados foram gerados em 2011 e no primeiro semestre de 2012.

Como destaca Cavalcanti, na pesquisa aplicada paga-se, muitas vezes, um ônus por ter de enfrentar o desafio de realizar diferentes atividades ao mesmo tempo (CAVALCANTI, 2006). Passamos por esses desafios que, sem dúvida, acarretam um trabalho a mais na intensa rotina da sala de aula, mas conseguimos conciliar as atividades de ensino e pesquisa, registrando conversas, fazendo entrevistas informais, tomando nota dos eventos observados (em algumas ocasióes nos intervalos das aulas ou depois delas) e sistematizando e analisando os instrumentos elaborados durante as aulas.

Nosso contexto de trabalho e estudo é o Colégio de Aplicação da Universidade Federal de Santa Catarina, mas buscamos refletir sobre realidades outras, algumas mais complexas e diferenciadas daquelas em que atuamos. O projeto tem um cunho etnográfico e o fato de nossos registros provirem de nossas salas de aula nos torna, além de nossos alunos e de toda a comunidade escolar, também participantes da pesquisa. Além das discussóes sobre práticas avaliativas, feitas na interaçáo direta com os alunos, nos reunimos para apresentar e discutir, entre nós, professoras, o 
resultado dessas tentativas de elaboração de instrumentos e sobre os critérios gerados, e problematizados, juntamente com os alunos. $\mathrm{O}$ arcabouço teórico utilizado como base para nosso estudo une preceitos da avaliação a partir da perspectiva de ensino e aprendizagem de línguas, com base especialmente na Linguística Aplicada, embora nossa discussão englobe também elementos da Educação em geral.

Numa relação constante entre proposição e aprendizado, vamos construindo o que Pennycook chama de "constante e recíproca relação entre teoria e prática” (PENNYCOOK, 2001, p. 3) de modo que através do desejo, do pensamento e da ação, criamos um espaço para alcançar a práxis educativa.

Nessa construção, duas perguntas partilhadas por nós foram essenciais e motivadoras para o projeto: a) Como podemos fazer para desenvolver critérios, juntamente com nossos alunos, de modo que, eles compartilhem da elaboração de instrumentos, participando efetivamente do processo de avaliação? e b) Como podemos fazer com que o aluno compreenda que o processo avaliativo na sala de aula de línguas estrangeiras/adicionais deve e pode ajudá-lo, ao contrário de prejudicá-lo?

Além desses questionamentos, preocupamo-nos em tornar nossa avaliação mais inclusiva; em discutir maneiras de professores e alunos saberem se houve aprendizagem e em modos de discutir os resultados da avaliação com todos os envolvidos nesse processo pedagógico. Consideramos que, por meio dessas tentativas, podemos nos movimentar entre os questionamentos e a divulgação de resultados, uma vez que não trabalhamos com a ideia de um modelo teórico único e tampouco com a ideia de conclusóes como verdades inquestionáveis (CAVALCANTI, 2006). Na seção seguinte, apresentamos algumas dessas tentativas.

\section{A elaboração de instrumentos}

Para elaborar instrumentos de avaliação que pudessem ser condizentes com o ensino e aprendizagem de línguas como uma prática social, no contexto micro da sala de aula, tornou-se necessário uma discussão com os alunos sobre o uso de línguas na sociedade contemporânea. Importava falar com cada grupo que a globalizaçáo e o avanço da tecnologia trouxe novas exigências de trocas transnacionais e que essas mudanças também precisavam refletir sobre os processos de ensino e aprendizagem de línguas. 
Como a avaliação é inerente a esse processo, tivemos que pensar também em novas formas de avaliar que fossem mais coerentes com o usos da linguagem que eles faziam em suas práticas sociais. Essa discussão foi importante para os alunos entenderem que queríamos avaliar o uso da LE/LA tendo em vista um ensino e aprendizagem que vai além da conquista do conhecimento puramente linguístico, mas que busca contemplar outras experiências para contribuir na formação do aluno (SHOHAMY, 2001).

Procuramos envolver os alunos de modo que eles tivessem uma percepção da avaliação como uma atividade autêntica que pode resolver problemas concretos, reais e inerentes ao processo de ensino e aprendizagem. Nas aulas de línguas, a conversa sobre aspectos da avaliaçáo passaram a ser compartilhados de modo mais efetivo com os alunos, que começaram a se manifestar mais livremente sobre suas dúvidas a respeito do modo como eram avaliados e para que serviam as avaliaçóes naquele contexto. Corroborando com estudos de Shohamy (2001), nossos alunos expressavam, reiteradamente, atitudes negativas e pouca confiança nos resultados das avaliaçóes.

Com base nas discussóes, achamos necessário definir alguns passos que pudessem tornar o processo avaliativo evidente e coerente para todo o grupo. Essas considerações nos levaram a estabelecer estas diretrizes:

a. Definição do propósito e dos objetivos do ensino e aprendizagem do tema/lição proposta;

b. Definição do propósito da avaliação (avaliação da aprendizagem, de rendimento e/ou avaliação para diagnóstico, por exemplo);

c. Definição da tarefa, da atividade, do projeto que se quer avaliar;

d. Definição dos conteúdos relacionados com as habilidades e competências que serão avaliadas;

e. Definição do modo de administração da avaliação;

f. Definição do modo de interpretação dos resultados;

g. Definição sobre como relatar os resultados.

Dessa forma, discutimos com os alunos como deveríamos proceder em relação a cada uma dessas diretrizes. A partir dessas discussóes, desenvolvemos instrumentos avaliativos, dentre os quais apresentamos aqui alguns exemplos ilustrativos. A apresentação desses instrumentos está organizada da seguinte forma: primeiro, descrevemos três exemplos de atividades e o processo de elaboração de instrumentos para o registro de 
avaliação do desempenho dos alunos em relação a elas. Desses exemplos, dois são da sala de aula de inglês e um da sala de aula de espanhol. Em seguida, destacamos dois outros instrumentos, o portfólio, com reflexôes acerca de seu uso na sala de alemão e o diário de aprendizagem, com reflexóes acerca de seu uso nas aulas de inglês.

O processo de elaboraçáo, as atividades e alguns instrumentos de registro de avaliaçáo na sala de aula de línguas

a) Instrumento de registro da avaliaçáo de pares, em trabalhos em grupo com alunos do Ensino Médio.

Nesse primeiro exemplo, apresentamos um instrumento de registro da avaliação de trabalhos em grupo, desenvolvido com a colaboração de alunos do $1^{\circ}$ ano do Ensino Médio. $\mathrm{O}$ projeto em que estavam sendo avaliados foi denominado Voluntary work. A atividade proposta vislumbrava o desenvolvimento de um projeto de cunho social em comunidades vizinhas. Além de desenvolverem o trabalho social, que deveria ser criteriosamente elaborado, os alunos deveriam pô-lo em prática e apresentar tanto o processo, como o resultado, para seus pares e para a professora. Foi acordado, no grande grupo, entre outros aspectos, que a apresentaçáo deveria ser feita com o uso de recursos visuais ou através de qualquer tipo de manifestaçáo artística como teatro, pintura, música etc. A avaliação seria feita pelos pares e, para tanto, os critérios seriam desenvolvidos, de modo colaborativo, no grande grupo. E assim foi feito. Na discussão sobre os critérios, os alunos apontaram os aspectos que consideravam relevantes e que deveriam constar na avaliação. Esses aspectos foram sendo registrados no quadro pela professora à medida que os alunos iam manifestando suas opinióes.

Esse registro foi feito, em Inglês, de modo que aquele momento se tornasse mais um espaço de aprendizagem da língua estrangeira/adicional. As sugestóes dos alunos, registradas no quadro, foram fotografadas e, mais tarde, editadas pela professora e transferidas para uma ficha de avaliação (Figura 1). Uma aula antes do momento da apresentação da atividade, os alunos tiveram acesso a essa ficha e puderam expressar suas opiniôes em relação a sua edição. Após alguns ajustes, todos concordaram com o modo como os critérios haviam sido editados. 
Durante a exposição dos trabalhos, os alunos utilizaram essa ficha de avaliação, criada com sua participação direta, para avaliarem o desempenho de seus pares. Segundo o registro feito pela professora e pelos próprios alunos, essa foi uma experiência muito significativa, uma vez que eles puderam refletir sobre processo avaliativo e participar ativamente dele. Em contraste com uma prática muitas vezes utilizada para propósitos disciplinares, a avaliação seguiu os princípios de colaboração, permitindo que os alunos exercessem um papel ativo e participativo em todo o processo, discutindo e enfatizando a heterogeneidade da sala de aula (LUCENA, 2012). Especialmente durante a discussão dos critérios, o grupo precisou lidar com diferentes concepçôes: como avaliar a pronúncia no uso da língua estrangeira/adicional ou como definir originalidade e criatividade, o que garantiu uma relevante discussáo sobre as diferenças individuais e as diferentes noçóes de proficiência no uso da língua inglesa no Brasil do século XXI.

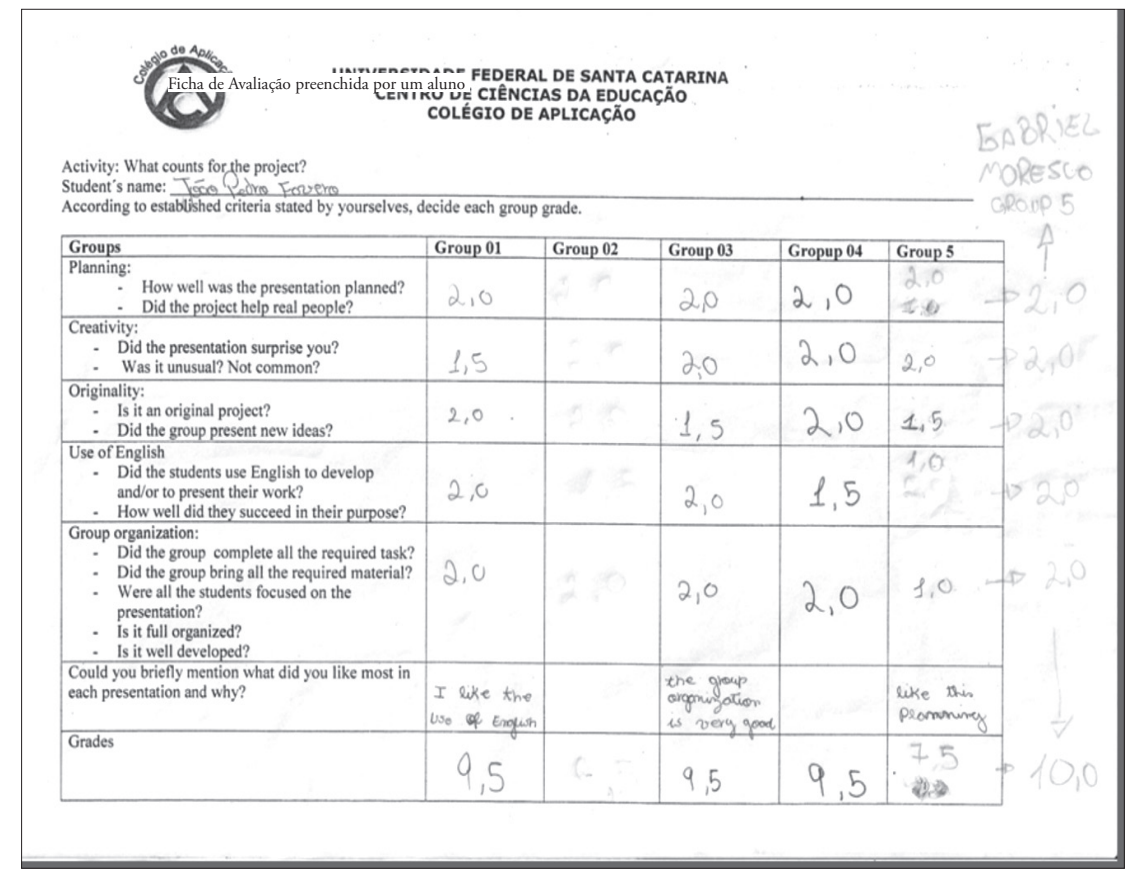

Figura 1. Ficha para registro da avaliação de pares, em trabalhos em grupo. Obs: $\mathrm{O}$ espaço (rabiscado) na margem direita da ficha de avaliação foi utilizado pelo aluno-avaliador para enfatizar e diferenciar suas inferências acerca de um dos componentes do grupo. 
b) Instrumento de registro da avaliação de pares, em trabalhos em grupo de uma apresentaçáo oral com alunos do Ensino Fundamental, nos anos finais

Nesse segundo exemplo, os critérios do instrumento de registro de avaliação foram estabelecidos pelos alunos do $6^{\circ}$ ano, com o auxílio da professora, para que ele fosse usado na avaliação da apresentação oral e na confecçáo do cartaz produzido por cada grupo. Os alunos assistiram ao filme Procurando Nemo, pois o trabalho apresentado tinha como objetivo divulgálo. Os aspectos considerados importantes por eles, para a apresentaçáo e as informaçóes relevantes que deveriam constar nos cartazes, foram registrados pela professora no quadro negro. Cada critério era anotado com uma cor diferente para que os alunos pudessem identificar qual era a ordem estabelecida; em seguida, copiavam na ficha de registro de avaliação, em branco, que haviam recebido individualmente (Figura 2).

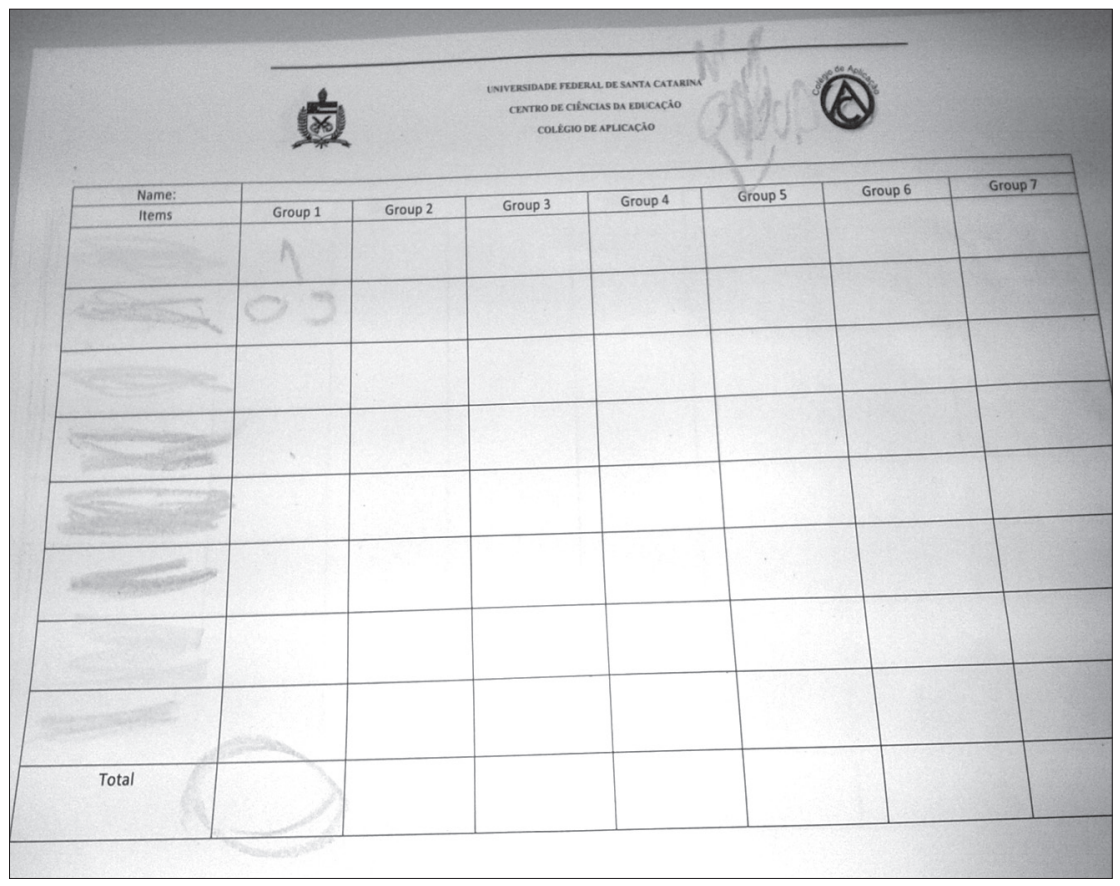

Figura 2. Instrumento de registro da avaliação de pares, em trabalhos em grupo. 
Os critérios estabelecidos pelos alunos foram os seguintes:

a) Se o cartaz era atraente ( 2,0 pontos);

b) Se as informaçóes contidas nos cartazes estavam organizadas (1,0 ponto);

c) Se os grupos haviam incluído figuras ilustrativas do filme $(1,0$ ponto);

d) Se os grupos haviam criado frases e não simplesmente copiado frases prontas (2,0 pontos);

e) Se os grupos foram criativos ( 2,0 pontos);

f) Se os alunos demonstraram confiança na hora da apresentação $(1,0$ ponto);

g) Se os alunos se comportaram bem durante a apresentação do próprio grupo (1,0 ponto);

h) Se todos os membros do grupo participaram da execuçấo da atividade (1,0 ponto);

Após escreverem esses critérios em seu caderno, os alunos avaliaram cada grupo com base na pontuação estabelecida para os critérios, pintando na ficha com as cores respectivas a cada um deles. Depois das apresentaçóes, foi feita a apuração das notas com a ajuda dos próprios alunos, por revezamento. Um aluno anotava as notas no quadro, outro as ditava, outro conferia se esse último estava ditando as notas corretamente, já que elas eram verbalizadas em inglês. Enquanto isso, outro aluno conferia se as notas estavam sendo registradas no quadro corretamente pelo colega, ao mesmo tempo em que um outro companheiro fazia os cálculos.

De acordo com a manifestação dos alunos, em relação ao consenso entre eles sobre as notas atribuídas, pode-se perceber que houve uma conscientizaçáo do grupo sobre o quanto é importante estabelecer certos critérios antes de se avaliar qualquer atividade.

Novamente, essa prática permitiu que os alunos agissem de forma democrática, fazendo com que eles participassem da discussão sobre quais aspectos da linguagem seriam avaliados e sobre as expectativas do grupo em relação à apresentação final do trabalho. A discussão e os argumentos dos alunos, durante a elaboraçáo de critérios, provocou mudanças na sua atitude, pois eles demonstraram confiança no processo, concordaram com o que foi feito e compreenderam os resultados finais. 
c) Instrumento de registro da avaliaçáo de pares, em trabalhos em dupla, com alunos do Ensino Fundamental, nas séries finais.

Esse terceiro exemplo apresenta um instrumento de registro criado pelos alunos da $6^{a}$ série, em colaboraçáo com a professora para avaliar a apresentaçáo do resultado da pesquisa, baseada na temática Las Casas en Brasil. O objetivo desse trabalho era identificar alguns tipos de moradias existentes nas regióes brasileiras. Divididos em pares, os alunos receberam, através de sorteio, tipos de moradias do Brasil. A partir daí, receberam também um roteiro da professora para ajudar na preparação do seu trabalho, que deveria ser pesquisado na internet e apresentado em data-show. Nesse roteiro, constavam as informaçóes que cada dupla deveria pesquisar sobre os tipos de moradia categorizados em favela, casa de pau a pique, de alvenaria, de madeira, de palha e palafitas. As informaçóes a pesquisar eram basicamente estas: 1) Que materiais são usados na construção dessa moradia?; 2) Como é o processo de construção dessa moradia?; 3) Em que regióes do Brasil encontramos esse tipo de moradia?

Durante a elaboração do trabalho, os critérios de avaliação foram definidos pelos alunos, com o auxílio da professora, os quais foram todos adicionados à ficha de avaliaçáo preenchida em sala de aula, no momento da apresentação de cada equipe. Entre os critérios definidos pelos alunos, três deles surgiram, imediatamente, no início da discussão: 1) o trabalho deveria valer de 0 (zero) a 10 (dez); 2) deveria haver uma nota individual pela apresentação oral; 3) deveria haver uma nota por dupla, pela preparação do trabalho escrito. Outro critério enfatizado pelos alunos foi a participação: os companheiros seriam avaliados pela participação e colaboração durante a sua apresentaçẫo e a apresentação dos colegas. Os demais critérios acordados pelo grupo podem ser conferidos na própria ficha de avaliação (Figura 3).

Após as apresentações e respectivas avaliaçóes, a professora pediu aos alunos que expressassem sua opinião sobre o instrumento de registro de avaliação usado. Alguns alunos disseram que gostaram de avaliar e ser avaliados dessa maneira, utilizando esse instrumento. Outros disseram que não se sentiam à vontade com esse tipo de avaliação, preferiam que o professor atribuísse a nota.

Esse comportamento dos alunos nos levou a refletir sobre a posiçáo de poder do professor/a de línguas, perpetuada e legitimada na sociedade como a autoridade máxima, cuja fluência permite a ele/ela fazer inferências 
sobre a proficiência e o uso da língua segundo seus padróes individuais. A postura dos alunos nos chama a atenção, pois mesmo em sociedades pósmodernas, multiculturais, onde o conhecimento é relativo e fluido, e onde grupos - linguísticos e outros - exigem legitimidade, respeito, identidade e direitos (SHOHAMY, 2001, p. 160), a autoridade das avaliaçôes, especialmente com relação ao uso da língua estrangeira/adicional, ainda dificulta um envolvimento de todos os envolvidos no processo de ensino e aprendizagem.

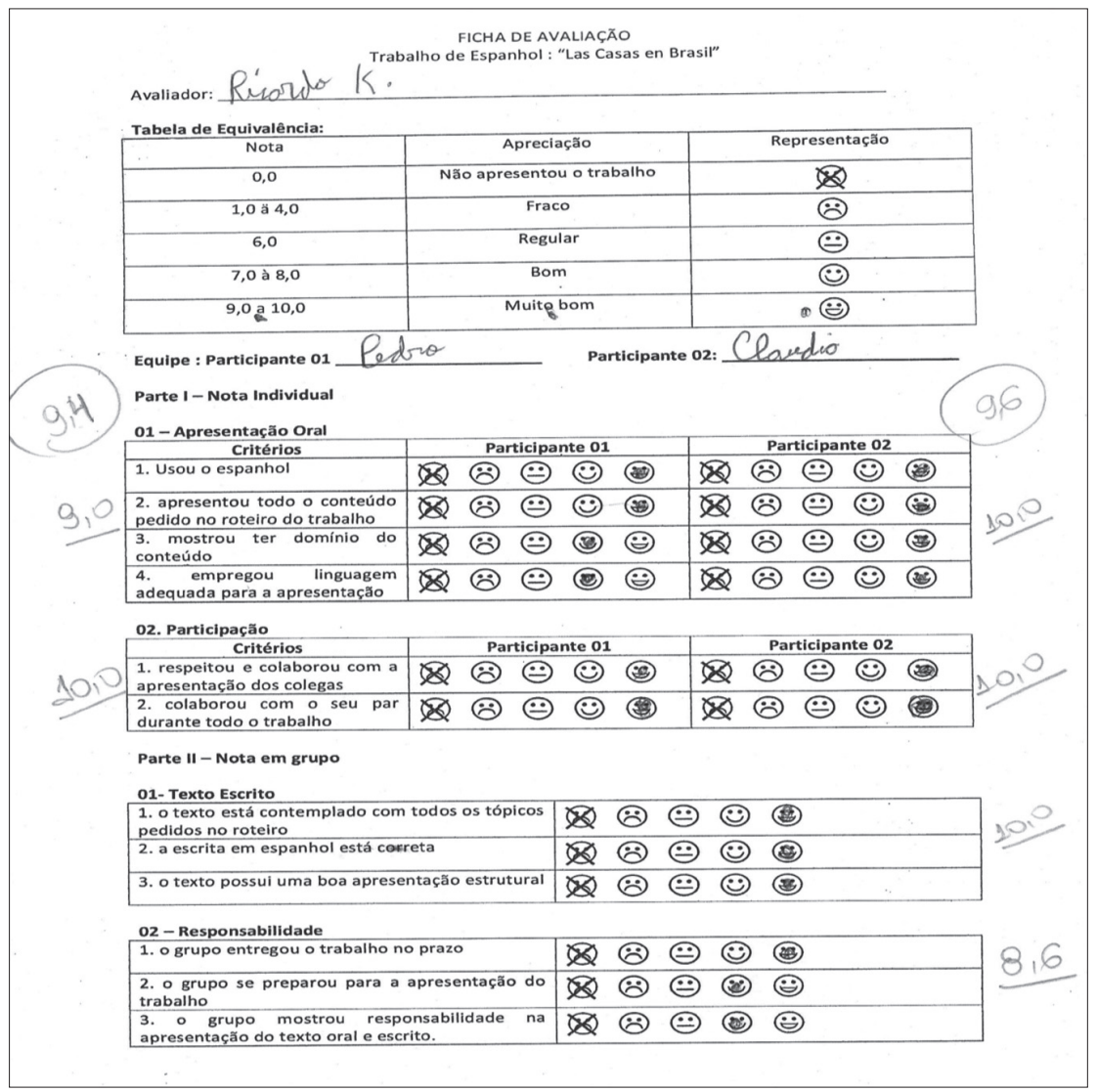

Figura 3. Instrumento de registro da avaliação de pares, em trabalhos em dupla, com nomes fictícios. 
No entanto, importa ressaltar que foi unânime a opiniāo positiva do grupo em relação à chance que lhes foi dada de construir os critérios pelos quais seriam avaliados. Pode-se dizer que uma possível falta de hábito dos alunos, em ter incluídas suas vozes no processo avaliativo, faça-os estranhar a mudança de algumas normas, mas isso não os impede de ver a relevância disso e de passar a compreender a mudança de um paradigma de avaliação centrado somente no professor para um paradigma que permite suas opinióes.

Ao repassar à turma a média dos trabalhos atribuída a partir das fichas preenchidas pelos próprios alunos, a professora comentou o fato de as notas confluírem com as notas atribuídas por ela e destacou as vantagens de se fazer uma avaliação com critérios estabelecidos pelo grupo.

Chamamos a atenção aqui para um problema que houve com essa ficha de registro quanto à atribuiçấo de peso a cada critério estabelecido. No momento da edição, como a pontuação dos critérios não havia sido discutida com o grande grupo, a professora resolveu delimitar uma pontuação de 1,0 a 4,0 para uma apresentação considerada "fraca"; 6,0 para uma apresentação "regular"; de 7,0 a 8,0 para uma apresentação "boa" e de 9,0 a 10 para uma apresentação "ótima". O problema foi identificado na hora de somar as notas. Conforme a configuração inicial da ficha de registro de avaliação, tornou-se impossível saber que valor numérico foi atribuído pelo avaliador, já que o conceito "fraco" havia sido definido como representativo de uma escala de 1,0 a 4,0. Sendo assim, na hora de somar os valores, a professora decidiu considerar o valor mais alto nos critérios que mostravam essa variabilidade. Esse fato nos levou a repensar sobre a necessidade de discutir com o grupo também o valor numérico referente a cada conceito, uma vez que a instituição exige o registro quantitativo da avaliação.

Essas atividades foram apresentadas aqui com o objetivo de exemplificar a nossa prática local, apresentando a sua sequência e as limitaçôes encontradas por nós durante o seu desenvolvimento. Abaixo, apresentamos algumas consideraçóes prévias sobre dois outros instrumentos que estâo sendo atualmente elaborados em conjunto com os alunos: o portfólio na sala de aula de alemão, e os diários de aprendizagem na sala de aula de inglês.

Portfólio como instrumento de avaliaçáo da aprendizagem na sala de aula de alemáo

O portfólio, além de guardar uma coleção de trabalhos que demonstram o progresso e os esforços do aluno no processo de aprendizagem, é 
importante para ele refletir sobre o seu aprendizado e sobre a sua relação com a nova língua, a cultura e suas práticas sociais historicamente situadas. Esse instrumento avaliativo está sendo utilizado, de forma sistemática, nas aulas de alemáo do $8^{\circ}$ ano, e os resultados mostram que, através dele, os alunos têm se envolvido mais ativamente no processo de ensino e aprendizagem dessa língua. Além disso, eles parecem ter adotado uma nova postura em relaçáo à avaliação em sala de aula, demonstrando um maior entendimento sobre os objetivos da LA/LE em suas práticas cotidianas (GARCEZ; SCHALLATER, 2009). Por meio da discussão e reflexão sobre a produção de seus trabalhos, o grupo tem observado que os dados utilizados para a inferência sobre o seu desempenho têm sido mais coerentes com o seu comportamento e com o uso da língua dentro e fora da sala de aula de alemão. Esse instrumento tem encorajado a produção daquilo que os alunos acreditam ser o que melhor descreve seu desempenho e tem ajudado a tornar mais significativo o aprendizado de alemáo na escola.

Os grupos têm se envolvido para estabelecer passos e objetivos que pretendem alcançar e, para tanto, primeiro foi feita uma discussão sobre o que é uma avaliação através de um portfólio. Em seguida, foi decidido quantos trabalhos seriam avaliados por trimestre, o formato deles (pesquisas, projetos - individuais ou em grupos - entrevistas, atividades de compreensão oral, testes escritos, entre outros). Também foi decidido se o portfólio seria uma caixa, uma pasta ou outro tipo de arquivo. A professora deixou o aluno escolher isso e muitos personalizaram os seus portólios.Porém, o mais importante foi a discussão acerca dos critérios para as notas e a combinação de horários para as exposiçóes e apresentaçóes dos alunos. Além disso, o grupo foi orientado a refletir sobre o processo de aprendizagem e sobre o quanto esse processo constitui uma açáo de responsabilidade conjunta, assim como qualquer outra ação social.

O portfólio foi utilizado como uma maneira de aproximar o conteúdo estudado à realidade do aluno, estimulando-o a falar sobre si mesmo: sua família, seus hobbies, seus gostos e interesses. Ao término de cada lição, os alunos realizaram autoavaliaçôes que foram sendo incluídas no portfólio, e nas quais fizeram reflexóes sobre o que haviam aprendido, de que haviam gostado mais, em que podiam ter obtido melhor resultado e do que lembravam espontaneamente.

Observamos que o portfólio fortaleceu a autoconfiança e a autocrítica, tanto dos alunos como da professora, contribuindo para um aprendizado 
mais produtivo e auxiliando na responsabilidade de organização do material escolar. Os alunos demonstram hoje mais envolvimento com a disciplina e uma preocupação maior com o seu aprendizado. Sendo assim, concluímos que o portfólio pode ser uma importante ferramenta não só na avaliação na sala de aula de línguas, mas também na formação do indivíduo como um todo, pois possibilita outros tipos de aprendizado, tais como o fortalecimento da identidade, a autocrítica e um maior entendimento do uso da LE/LA em sua realidade social específica.

\section{Diário de aprendizagem e avaliação em grupo}

O diário de aprendizagem, outro exemplo de instrumento utilizado por nós, constitui-se, basicamente, de um caderno no qual os alunos registram informaçóes sobre a sua aprendizagem. Ele tem sido utilizado sistematicamente nas aulas de Inglês, mais especificamente, em uma turma do $6^{\circ}$ ano. Após uma discussão sobre a finalidade do seu uso, os registros são feitos pelos alunos, preferencialmente, uma vez por semana, e essa prática tem possibilitado a reflexão sobre as aulas de línguas, de modo constante, por alunos e professora.

Como o registro é pessoal, foi sugerido aos alunos que fizessem com que o diário refletisse a identidade de cada um deles. Para tanto, eles o compuseram de acordo com o estilo, as características e perspectivas de cada um. Embora possa parecer irrelevante, o fato de identificarem o caderno de acordo com sua personalidade contribuiu para consolidar o sentimento de agência dos alunos em relaçáo ao processo avaliativo, uma vez que essa prática propiciou o relato de suas experiências pessoais durante o processo de ensino e aprendizagem de LE/LA (BLOCK, 2003).

$\mathrm{O}$ uso desse tipo de instrumento tem propiciado ao aluno a reflexão sobre o que está aprendendo, e contribui para que ele estabeleça vínculos entre a escola e a vida. A discussáo em sala sobre o uso do diário envolve a reflexão em conjunto sobre os objetivos da aula, sobre o andamento das liçóes durante a semana e sobre o desempenho de cada aluno/a quanto à aprendizagem de línguas dentro e fora da sala de aula. Para tanto, discutimos no grupo o que é ser proficiente naquele contexto de ensino de línguas e no meio em que vive. Utilizando uma linguagem simples, refletimos juntos sobre o que eles aprenderam e o que eles conseguem fazer com a LE/LA no cenário social em que estão inseridos. Com base em suas respostas, vamos reorientando e adequando o programa. 
Nesse instrumento, notamos que a orientação dada aos alunos, com relação aos aspectos que podem ser relatados, é fundamental para que ele se torne uma prática pedagógica efetiva. Nesse sentido, a professora pode sugerir que os alunos reflitam e escrevam sobre os momentos e as abordagens em aula que favorecem mais a aprendizagem; que registrem aquilo que aprenderam; que falem sobre as atividades que os ajudaram mais; que indiquem as formas de interação mais interessantes; que falem sobre o que têm aprendido e sobre o quanto eles se sentem, ou não, seguros em relação ao uso da LE/LA. Por fim, importa que eles registrem tudo aquilo que consideram passível de revisão.

Os registros e relatos dos alunos foram utilizados pela professora como insumo para novas discussóes com o grupo (por vezes, de acordo com a situação, alguns alunos foram chamados para uma conversa individual). Desse modo, o grupo pode ter a clareza sobre o que era esperado dele a respeito da natureza do ensino e aprendizagem de línguas estrangeiras/ adicionais na escola e teve a oportunidade de expressar suas expectativas também em relação àquilo que os alunos esperam da escola com o ensino de línguas.

\section{Consideraçóes finais}

Consideramos que diferentes instrumentos avaliativos, na sala de aula de língua estrangeira/adicional, permitem ao aluno ampliar as possibilidades de avaliação e não o prendem a um instrumento único, como as tradicionais provas, por exemplo. Pela análise deste material produzido em sala de aula, podemos concluir que estes tipos de instrumentos fazem com que o aluno reflita criticamente sobre o que ele está aprendendo e como está o seu desempenho, destacando aspectos do processo de ensino e aprendizagem que muitas vezes não são considerados no cotidiano escolar. Temos percebido que a reflexão e o uso de instrumentos diferenciados têm despertado nos alunos uma maior motivação em participar das atividades e, sobretudo, tm permitido que eles entendam quais aspectos são, de fato, avaliados em suas produçôes. Os exemplos apresentados aqui têm sido aprimorados e utilizados com outras turmas. Além disso, seguimos experimentando novos instrumentos e novas práticas de acordo com as necessidades locais.

Acreditamos, portanto, que a diversidade de práticas tem comprovado que todos os alunos podem aprender os conteúdos estudados, 
embora nem todos possam demonstrar isso no mesmo dia, exatamente do mesmo modo.

Nessa perspectiva, vamos pensando, repensando, desinventando e reconstruindo nossas práticas avaliativas, questionando conceitos naturalizados e procurando elaborar instrumentos que sejam condizentes com as expectativas dos alunos em relaçáo ao uso da LE/LA em sua vida cotidiana. Sabemos que a realidade homogeneizante das salas de aula não deixa muito espaço para o professor pensar em especificidades, mas acreditamos que algumas iniciativas, como promover a agência daqueles que ficam às margens em processos avaliativos, dando-lhes voz e espaço para a discussão de critérios e de resultados da avaliação, podem contribuir sobremaneira para maximizar o sentido educacional da avaliação na sala de aula de LE/LA.

\section{Referências}

BLOCK, D. Block, D. The Social Turn in Second Language Acquisition. Washington, D.C: Georgetown University Press. 2003.

CAVALCANTI, M. C. Um olhar metateórico e metametodológico em pesquisa em Linguística Aplicada: implicações éticas e políticas. In: MOITA LOPES, L. P. (Org.). Por uma Linguistica Aplicada Indisciplinar. São Paulo: Parábola Editorial, 2006. p. 233-252.

GARCEZ, P. Produção de conhecimento, uso da linguagem e ensino de língua: desafios para a relação entre linguistas aplicados e sociedade. In: IX Congresso Brasileiro de Linguística Aplicada, ALAB. Conferência. Rio de Janeiro: [s.n.], 2011.

LUCENA, M. I. P. Razóes e realidades no modo como as professoras de Inglês como lingua estrangeira de escola pública avaliam seus alunos. Tese (Doutorado em Letras) - Programa de Pós-graduação em Letras, Universidade Federal do Rio Grande do Sul, Porto Alegre, 2006.

LUCENA, M. I. P. Avaliação no ensino de línguas, formação de professores e sociedade contemporânea. Anais Eletrônicos do Congresso Brasileiro de Linguística Aplicada, v. 1, n. 1, 2012.

PENNYCOOK, A. Critical applied linguistics: a critical introduction. London: Lawrence Erbaum Associates, 2001. 
SCARAMUCCI, M. V. R. A Proficiência em LE: consideraçôes terminológicas e conceituais. Trabalhos em Linguística Aplicada, [S.l.], n. 36, p. 11-22, 2000.

SCHLATTER, M.; GARCEZ, P. M. Linguas adicionais na escola: aprendizagens colaborativas em inglês. Erechim, RS: Edelbra, v. 1, 2012.

SCHLATTER, M; GARCEZ, P. M. Línguas Adicionais (Espanhol e Inglês). Rio Grande do Sul, Secretaria de Estado da Educação, Departamento Pedagógico (Orgs.). Referências curriculares do Estado do Rio Grande do Sul: linguagem, códigos e suas tecnologias. Porto Alegre: Secretaria de Estado da Educação, Departamento Pedagógico, v. 1, p. 127-172, 2009.

SHOHAMY, E. The Power of the tests: a critical perspective on the uses of language tests. London: Longman, 2001.

Recebido em: 30 jul. 2012

Aceito em: 22 out. 2012 